\title{
STANDARDIZED DATABASE FOR FLOOD RISK MANAGEMENT IN MOROCCO
}

\author{
Hassan TABYAOUI *, Meriam LAHSAINI and Fatima EL HAMMICHI \\ Natural Resources and Environment laboratory, Sidi Mohamed Ben Abdellah University, Fez, Polydisciplinary Faculty \\ of Taza, BP. 1223, Taza-Gare, Morocco. \\ hassan.tabyaoui@usmba.ac.ma
}

KEY WORDS: Flood, Inventory, Merise, GIS, Risk Management, Morocco

\begin{abstract}
:
Flood is considered to be one the worst kind of hazard. It has severe effects on human society in the form life losses, damages to property, roads, and on natural setting. The inventory of affected sites in Morocco is important for better risk management. This article describes the detailed process for creating, modeling, and designing the flood database. This design allows homogenization of data exchanges between national stakeholders and follows international standards for flood risk management. It is standardized and could be interoperable.
\end{abstract}

\section{INTRODUCTION}

Floods are the most common, most damaging and deadly natural disasters in the world each year (Pulvirenti, 2011). They are the source of nearly half of all natural disaster deaths in the last 50 years, and account for nearly one-third of global economic losses (James and Hall, 1986). These disasters result from periodic natural phenomena such as the monsoon or el niño, others are the result of particular circumstances (cyclones, typhoons, violent storms) and are aggravated by the climatic disturbances. At the scale of the Mediterranean basin, the risks of flood come in second row after the seismic risks, but they occupy however the first rank on the plane of frequencies of occurrences (Villevieille, 1997). Morocco, due to its geographical location in north-west Africa, and its climatic context, is subject to floods.

Some cause significant damage and undermine the socio-economic development of exposed areas. Various studies for risk management and characterization of the flood hazard have been developed. They are based on qualitative methods related to the morphology of the watercourse and quantitative methods for modeling and simulation of flood processes. Most of the methods and tools created are aimed more at insurers than at territorial managers or at real emergency planning. Inventory tests were undertaken using computer and GIS tools. Most studies focus on analyzing the causes of the risks of past floods and the location of individuals or vulnerable infrastructure, and to target risk areas and develop and reduction policies and measures risk. These studies are thus more oriented towards the risk prevention phase than towards the crisis management phase.
In order to make a detailed descriptive inventory of the various flooded sites with their spatial reference, we used the DBMS-Access for creating, consulting and updating data. This goal is accomplished through three stages:

- Establish a data dictionary in order to facilitate the recovery of the database;

- Implementation of a conceptual model of data according to the Merise method;

- Creation of a database and search interfaces for database information by geographical and thematic navigation (GIS).

This article describes the three steps above and how it follows the international exchange standards.

\section{DEVELOPMENT}

The scheme of creating the BD-Flood is based on Merise design. This method is based on the entityassociation model (Tardieu at el., 1985). This design is characterized by a succession of steps, to achieve a functional information system reflecting a physical reality.

- develop a data dictionary (DD) to have and administer a common language between the various flood risk management actors and a reference of all the studies carried out. For this reason, each concept of the data dictionary, called entity and each information of the data dictionary, called attribute, is described by a text proposing a common definition and its management rules. Tables 1 and 2 describe two examples of lexicon tables;

Table 1: Different scenario considered in the flood

\begin{tabular}{|l|l|l|}
\hline Code & Valeur & Definition \\
\hline ATE & very high & Hazard causes the first \\
\hline
\end{tabular}




\begin{tabular}{|l|l|l|}
\hline AE & hazard & $\begin{array}{l}\text { damage due to a speed higher } \\
\text { than } 2 \mathrm{~m} / \mathrm{s} \text { and an upper } \\
\text { water level to 1.50 m }\end{array}$ \\
\hline AM & $\begin{array}{l}\text { high hazard } \\
\text { medium } \\
\text { probability } \\
\text { Event with speed between 1 } \\
\text { h } \mathrm{s} \text { and } 2 \mathrm{~m} / \mathrm{s} \text { and water } \\
\text { height between } 0.80 \mathrm{~m} \text { and } \\
1.50 \mathrm{~m}\end{array}$ \\
\hline AF & $\begin{array}{l}\text { Hazard low } \\
\text { probability } \\
\text { between } 0.30 \mathrm{~m} \text { and } 0.80 \mathrm{~m} \\
\text { and speed between } 0.50 \mathrm{~m} / \mathrm{s} \\
\text { and } 1 \mathrm{~m} / \mathrm{s}\end{array}$ & $\begin{array}{l}\text { Flood event at a speed lower } \\
\text { than } 0.50 \text { (m / s) and water } \\
\text { depth less than 0.3 m }\end{array}$ \\
\hline AN & $\begin{array}{l}\text { significant } \\
\text { hazard }\end{array}$ & $\begin{array}{l}\text { Event with a return period of } \\
1000 \text { or the flooding } \\
\text { phenomenon is exceptional } \\
\text { flooded alluvial plain surface. }\end{array}$ \\
\hline
\end{tabular}

Table 2: Lexicon table: Region

\begin{tabular}{|l|l|}
\hline Code & Valeur \\
\hline REG_01 & Tanger-Tétouan-Al Hoceima \\
\hline REG_02 & Oriental \\
\hline REG_03 & Fès- Meknès \\
\hline REG_04 & Rabat- salé - Kenitra \\
\hline REG_05 & Beni Mellal- khénifra \\
\hline REG_06 & Casablanca-Settat \\
\hline REG_07 & Marrakech- safi \\
\hline REG_08 & Draa-Tafilalet \\
\hline EG_09 & Sous-Massa \\
\hline REG_10 & Guelmim-Oued Noun \\
\hline REG_11 & Laayoune-Saguia al Hamra \\
\hline REG_12 & Ed Dakhla-Oued ed Dahab \\
\hline
\end{tabular}

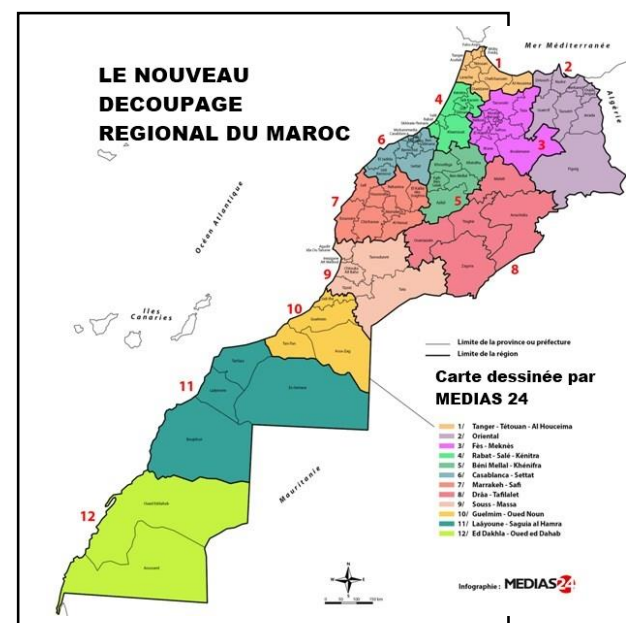

- Construct the conceptual data model (CDM) This model is used to describe information system data. It helps to identify the links between the data and produce a schematic representation (Koehl, 2010). For this study, the CDM focuses on the resulting data from the floodplain mapping and flood risk process. It consists, in total, of 68 tables. All tables and relationships are grouped into four conceptual classes: "Event", "Flooded Area", "Flood History" and "Flood Risk".

○ The "Event" conceptual class (Fig. 1): identifies the flood event in each risk area (name of flooded area, GPS-coordinates, history of floods, flood risk, watershed name, data sources). This table is in association with lexicons tables that serve as data dictionaries (flood type, watersheds, datum, projection system, ...);

- The "Flooded Zone" conceptual class includes data on the flood surface where spill overflows can spread in the floodplain and play an important role in flood capping. Some data are of a spatial character: flooded surface, hydrological basin, watercourse. Others are of attribute character: name of topographic maps, topography (surface, slope, elevation, ...), Scenario of Aléa taken into account, data sources, ... This table is associated with lexical tables, such as: land occupation (artificial, agricultural, bare, forest land), Permeability of land (Permeable, Semi Permeable, Waterproof), soil type related to the field lithology (shots, Hamri, Harch, Dehs, Biad, Rmel, ...), morphological type of a river (River, Wadi, Torrent, Stream, Channel), drain flow nature (Permanent, Seasonal, Episodic, Spasmodic, Intermittent, Torrential) ...;

○ The "flood history" conceptual class collects flood events in one place. The data includes information such as: Flood start date, Maximum daily rain, Flood duration in hours, Maximum flow in $\mathrm{m} 3$ / s, Water depth in $\mathrm{cm}$, Return time of the Flood History, name of Hydrological Station, name of Rainfall Station;

- The "Flood risk" conceptual class identifies issues related to humans, to infrastructures, to commercial activities, to urban activities, agricultural or industrial activities, to hydrological and hydraulic models and finally to flood protection works (e.g. dikes, dams, diversion canals, dynamic slowdown works). These models make it possible to quantify the overflow in the floodplain and the flow of the streams, the heights and water velocity for different return periods $(10,25,50,100$ years $)$.

The flood CDM that we developed is intended to be physically represented by the RDBMS. MS Access was used for the creation and management of the database and POWER AMC [6, 7] was used to check the consistency between the data and maintain data dictionary information system. 5 main forms group 36 tabs and sub-tabs have been created under MS-Access, allowing input and consultation of attribute data. 
- The "Event" input form includes all the data fields for event identification (Fig. 2).

o The "flooded zone" form represents the physical data concerning the flooded area such as the length, the surface, the elevation of the flooded basin as well as topological data allowing to automatically calculate certain parameters such as: the concentration time "tc" by the Formulas of Giandotti, Ventura, Kirpich, Van Te Chow. The equations can be found in [8 to 11].

- The "Flood History" form contains information on the historical floods of a past event. This form includes subforms to identify hydrometric or rainfall stations.

o The "Flood Risk" form allows users to quantify areas vulnerable to flood risk.

- The "Data Source" form contains the list of available sources used for the event. At the "Reference type", a lookup wizard lists the items available from the "data_source" table.

5 main query forms are also created to display some data contained in the tables and also do calculations on our data. They are conveniently searchable in the Access interface. SQL can help to query or manipulate our database. The success of this SQL language is due mainly to its simplicity and the fact that it relies on the conceptual schema to state queries by leaving the DBMS responsible for the execution strategy. From these forms, many possibilities are offered to the user. We cite some examples below:

- The cross sections which constitute the base on which all the hydraulic modeling of rivers are built (Fig. 3);

- The types of arts and protective structures (dikes, riprap, embankments, retaining walls) that were created in order to limit the extent of flooding;

- See the results of hydraulic modeling and analysis of hazard and risk;

- View photos of the flooded areas including the position of taking the picture.

The resulting database includes more than 3000 records. This data is used in a GIS software via ODBC connection (Open Database Connectivity). ODBC is a Microsoft-defined format for communication between Windows-based database clients and DBMSs market
(Fig. 4). The ODBC connection between MS-Access and ESRI $\odot$ ArcGIS (ESRI, 2011) allowed:

- update automatically, the cartographic database of geographic features and attribute data and standard way of interfacing an application to any database server;

- $\quad$ ability to apply simulation models and previously undefined queries;

- create well-defined spatial queries. Figure 5 shows an example of a query associating attribute and spatial data.

\section{Approach towards Standardization}

MS Access was used for the creation and management of the database and POWER AMC was used to check the consistency between the data. It is a design software, considered as a checklist of conceptual and logical models of data. It is a graphical tool (under Windows) of information systems design. It allows to implement the Merise method facilitating database creation steps and application development (Sybase, 2015). It is also the perfect tool for synchronizing perfectly with Java, Microsoft .Net, WSDL, XML, PowerBuilder, ebXML and other BPEL4WS platforms.

For this study, the XML document generated under Power AMC, is imported into the Sparx Systems Enterprise Architect software (Sparx, 2017) to provide a visual model of our database, based on the standard UML notation (Unified Modeling Language). The latter is a standardized modeling language standardized by the OMG (Object Management Group). It has already been adopted by some researchers developing information systems for natural hazards [14 to 17].

\section{CONCLUSION}

The database thus constructed, has continued to evolve with the advancement historical flood data entry work, hydrological and hydraulic calculations. This database is also designed to be scalable and supplemented or modified as and when new needs, such as: when an evolution of the field changes the floodplain area or flood risk or when improvements are made with new models or techniques 
The International Archives of the Photogrammetry, Remote Sensing and Spatial Information Sciences, Volume XLII-4/W16, 2019 6th International Conference on Geomatics and Geospatial Technology (GGT 2019), 1-3 October 2019, Kuala Lumpur, Malaysia

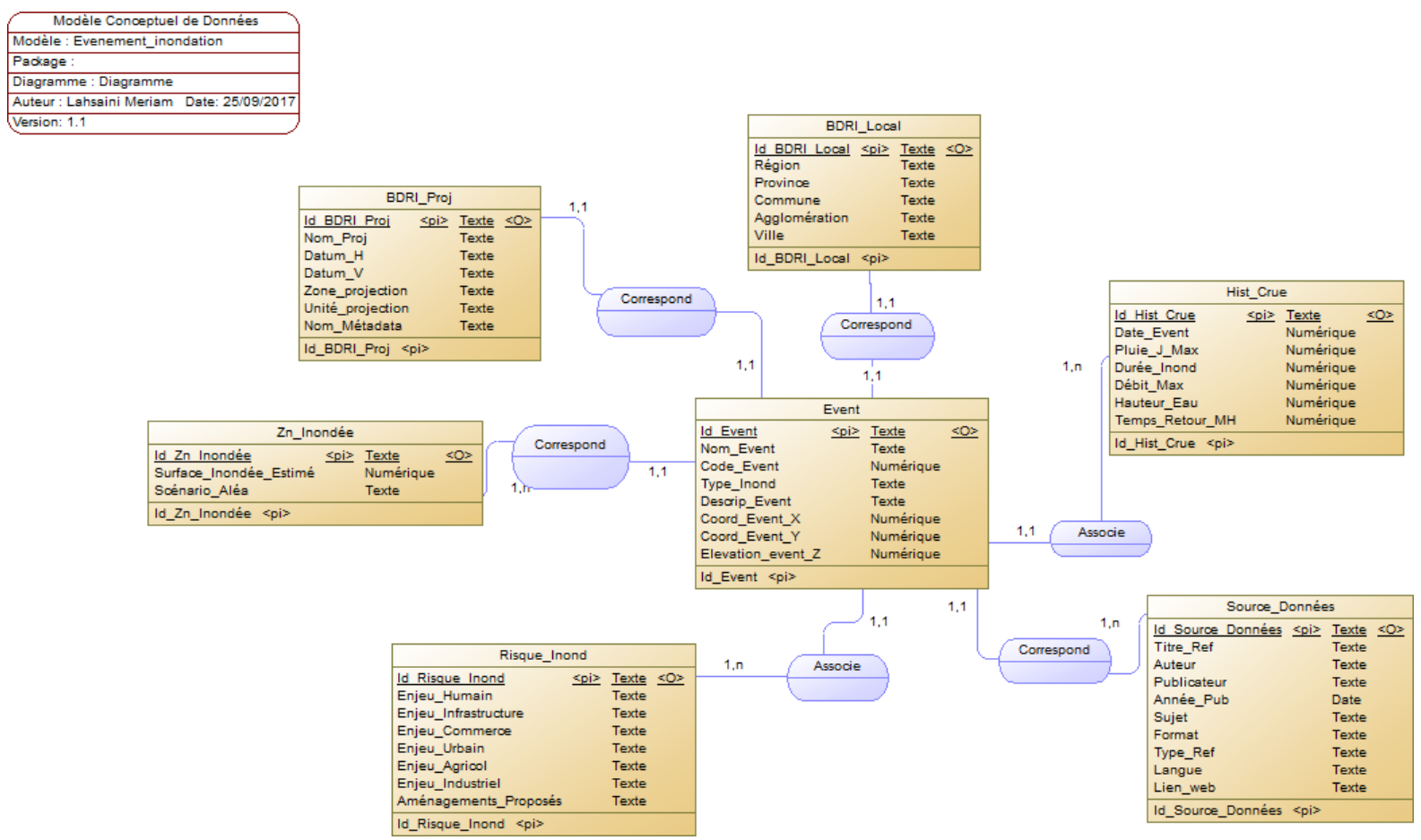

Fig. 1: Conceptual Data Model "Event" in PowerAMC

\begin{tabular}{|c|c|c|c|c|c|}
\hline Code évenement & 57 & & Nom événement & \multicolumn{2}{|l|}{ Sefrou } \\
\hline Bassin hydrographique & Sebou & 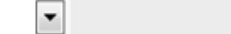 & Région & \multicolumn{2}{|l|}{ fes } \\
\hline Sous Bassin Principal & \multicolumn{2}{|l|}{ BV oued Aggay } & Province & \multicolumn{2}{|c|}{ Sefrou } \\
\hline Cours d'eau principal & \multicolumn{2}{|l|}{ Oued Aggay } & Commune & \multicolumn{2}{|l|}{ Sefrou } \\
\hline Zone_projection & Zone I (Nord Maroc) & $\bullet$ & Type d'inondation & \multicolumn{2}{|c|}{$\begin{array}{l}\text { Crues rapides des petits bassins de } \\
\text { montagne }\end{array}$} \\
\hline Coordonnée X & $\mid-4.85141$ & & \multirow[t]{2}{*}{ Description } & & \\
\hline Coordonnée Y & 33.8256 & & & & \\
\hline \multicolumn{2}{|l|}{ Zone inondée } & Historique des crues & \multicolumn{2}{|c|}{ Risques d'inondation } & Source de données \\
\hline
\end{tabular}

Fig. 2: Event Form 


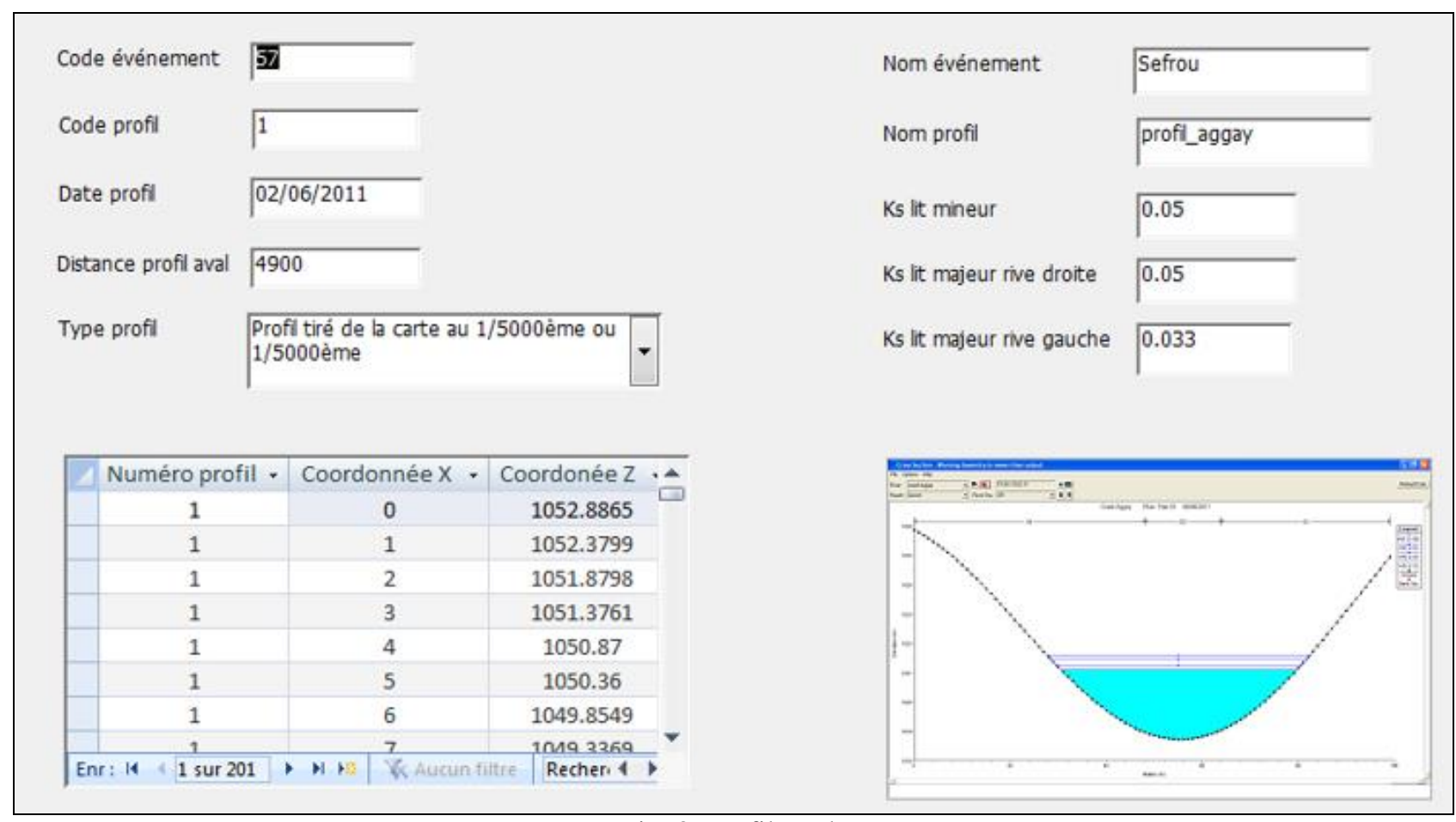

Fig. 3: Profiles tab

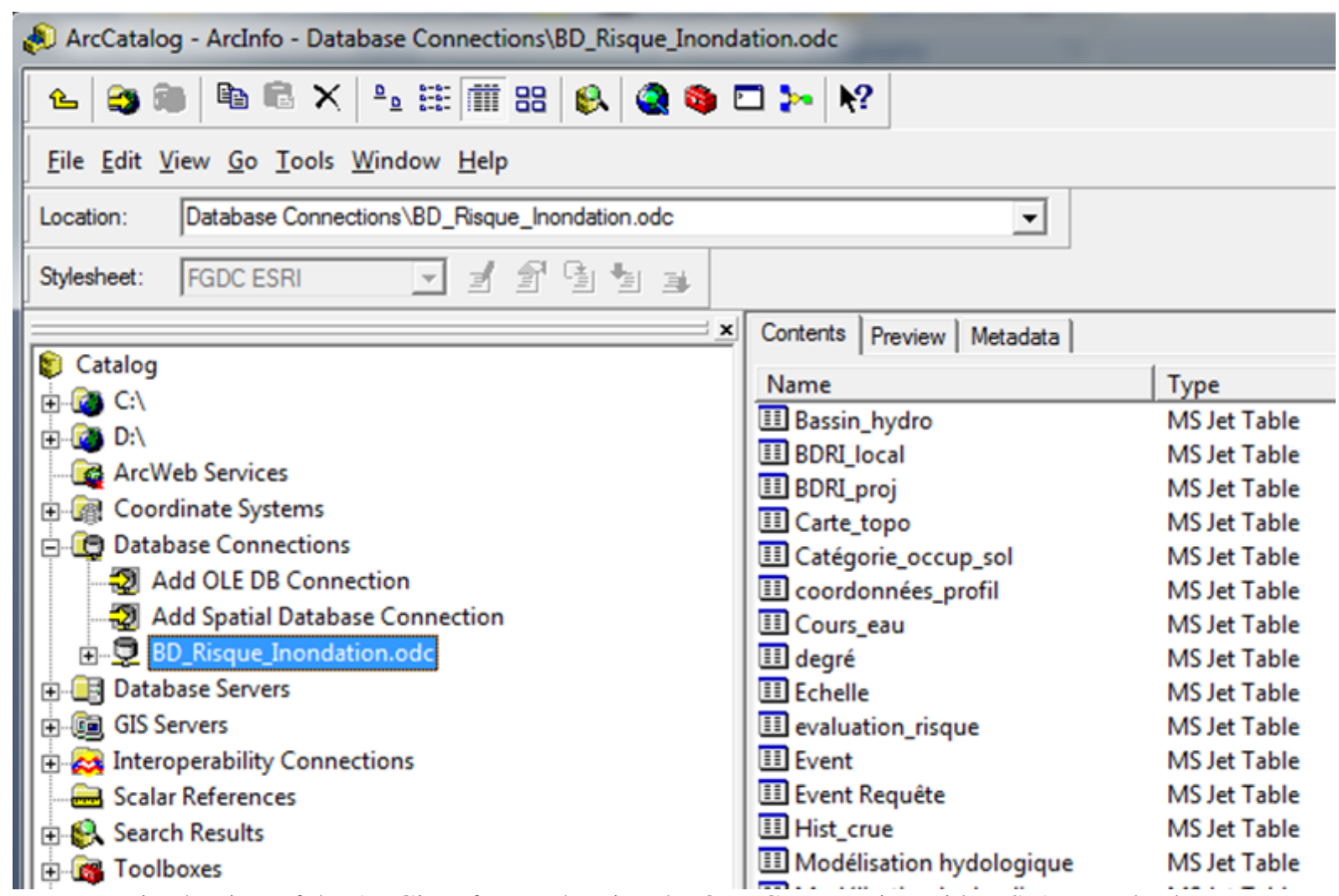

Fig. 4: View of the ArcGis software showing the ODBC connection with MS-Access database 


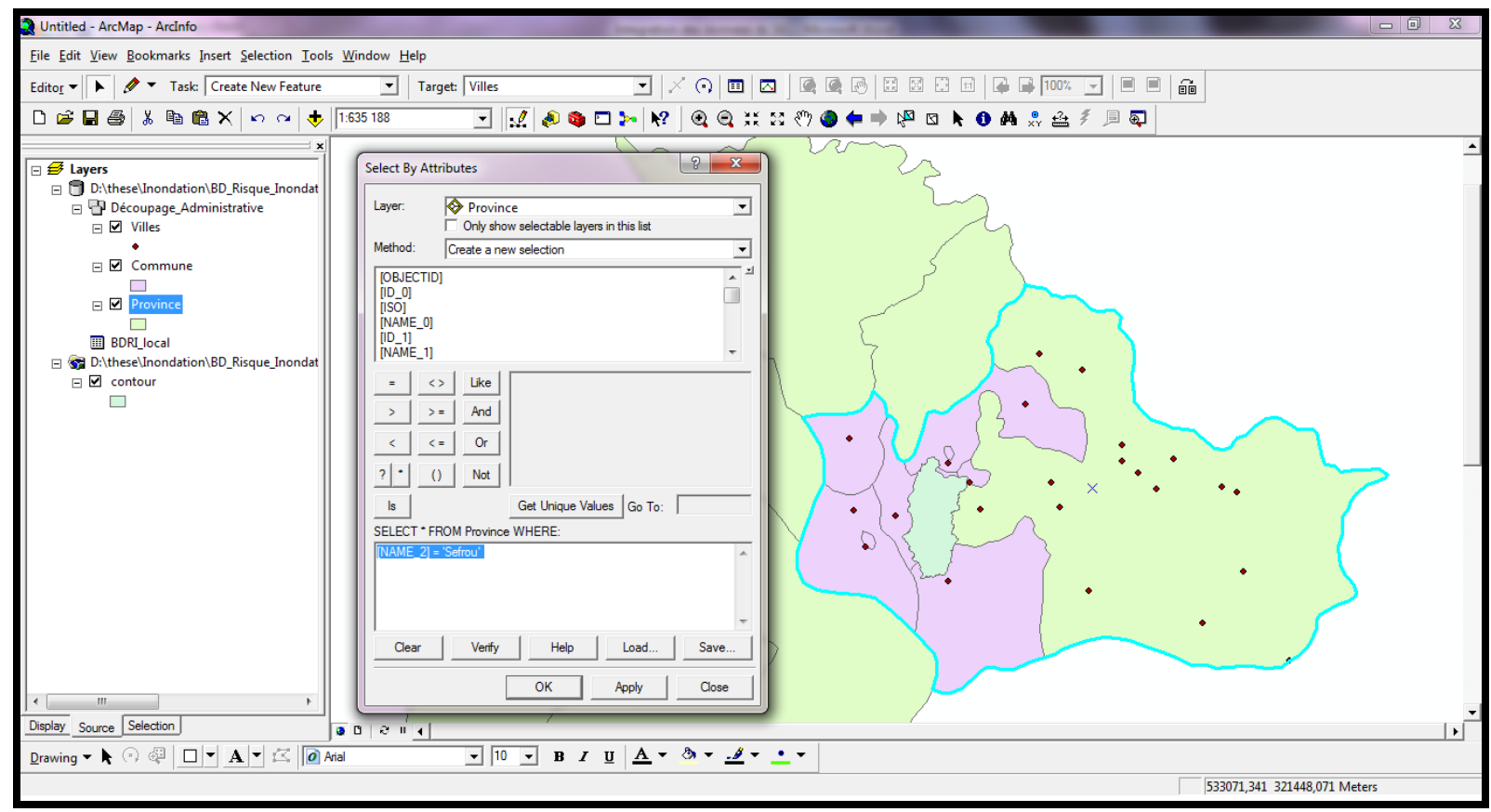

Fig.re 5 : Sélection par attributs

\section{REFERENCES}

Pulvirenti, al. An algorithm for operational flood mapping from Synthetic Aperture Radar (SAR) data using fuzzy logic. s.1. : Natural Hazards and Earth System Science, 11(2): 529540., $2011 b$.

James, L. and B. Hall, 1986, Risk information for floodplain management. J. Water Resources Plann. Manage., 112: 485499.

Villevieille A., 1997. Les risques naturels en Méditerranée . Editeur : Economica, Collection : Les fascicules du plan bleu, 160 pages, ISBN-10: 2717835156, ISBN-13: 978-2717835151

Tardieu, H., Rochfeld, A., Coletti, R., \& Vahée, P., 1985. La méthode Merise, Tome 2 : Démarche et pratiques.

Koehl M. A., 2010. How does morphology affect performance in variable environments? In Search of the Causes of Evolution: From Field Observations to Mechanisms. Princeton University Press, NJ. doi:10.586 , pp.177-191. In: P.R. Grant and B. Grant [eds.].

Sybase, 2015. SAP Sybase Tools: License Update.

ESRI, 2011. ArcGIS Desktop: Release 10. Redlands, CA, Environmental Systems Research Institute.

Sparx, 2017. http://sparxsystems.com/ 